\section{Prognostic factors for recurrence with unilateral recess-resect procedure in patients with intermittent exotropia}

SH Lim, JS Hong and MM Kim

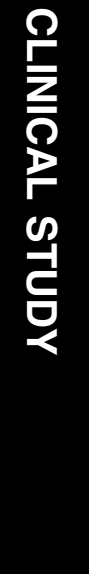

Conclusion In unilateral $R \& R$ procedures, increasing patient age at the time of surgery was associated with lower recurrence rates. Recurrence rates also increased with the immediate postoperative angle and with the postoperative angle of deviation at 1, 3, 6, and 12 months.

Eye (2011) 25, 449-454; doi:10.1038/eye.2011.12; published online 11 February 2011

Keywords: intermittent exotropia; recurrence; unilateral recess-resect procedure

\section{Introduction}

Intermittent exotropia is the most common form of exotropia and is more prevalent among Asians than among Caucasians. ${ }^{1-3}$ Exotropia is reported to occur at more than twice the rate of that of esotropia, particularly in Korea., As surgery results in better treatment outcomes than non-surgical treatments, such as orthoptics or occlusion therapy, it is performed in most cases in which surgery is indicated. ${ }^{6}$ Generally, patients showing an initial tendency toward exotropic drift postoperatively over time, and some of them are reported to have a recurrence of exotropia. ${ }^{2,7-9}$ In addition, as the success rate of surgery varies by studies (32.8-83.3\%), the exact prediction of the surgical outcome is difficult. .,10-12 $^{\text {. }}$

There have been a number of reports of possible prognostic factors affecting surgical outcomes, such as preoperative degree of exodeviation, ${ }^{13}$ duration of postoperative follow-up, ${ }^{7}$ surgical procedures, ${ }^{12,14}$ types of
Department of Ophthalmology, Yeungnam University College of Medicine, Daegu, South Korea

Correspondence: MM Kim, \#317-1 Daemyung-dong, Nam-gu, Daegu, 705-717, South Korea Tel: + 8253620 3441; Fax: + 82536265936 E-mail:mmk@ med.yu.ac.kr

Received: 20 October 2010 Accepted in revised form: 17 December 2010 February 2011

This paper was given as a presentation at a meeting and was presented at the AAPOS as a poster. Published online: 11 
exotropia, ${ }^{10,11,15}$ and stereopsis. ${ }^{16}$ However, controversies still abound. In particular, the age at surgery is subject to dispute because some studies advocated surgery at an early age ${ }^{17-19}$ whereas others claimed that early surgery is not desirable. ${ }^{8}$ Although many reports ${ }^{9,13,14,20}$ have stated that age at surgery for intermittent exotropia does not affect the surgical outcome, there are some reports ${ }^{8,17,18}$ identifying age as a prognostic factor. Thus, referring to age as a prognostic factor is debatable.

The success of strabismus surgery is known to be highly dependent on surgical procedures; thus, the success rates of surgeries performed in a single institute by a single surgeon are expected to be more statistically significant than those performed at multiple institutes by different surgeons. Studies on recurrence for cases in which surgeries were performed at single institutes using a single surgical procedure (unilateral R\&R) by a single surgeon are rare. Therefore, we analyzed factors that influence the surgical recurrence rate, particularly the patient age at the time of surgery when a unilateral $R \& R$ procedure, a type of $\mathrm{X}(\mathrm{T})$ surgery, was performed.

\section{Patients and methods}

\section{Patients}

We retrospectively reviewed the medical records of 489 subjects who received a unilateral $R \& R$ procedure between January 1991 and June 2007 at Yeungnam University Medical Center with more than 12 months of postoperative follow-up. Subjects with constant exotropia, a history of ocular surgery, A-V pattern strabismus, oblique muscle dysfunction, vertical strabismus, paralytic strabismus, strabismus with restricted motility, unilateral amblyopia, comorbidity (eg, nystagmus), or a systemic disease (eg, cerebral palsy) were excluded from the study.

\section{Preoperative evaluation}

All patients underwent a complete ophthalmologic examination before operation. A visual acuity test for every patient was conducted with correction of refractive errors. Prism and alternate cover tests with accommodative target fixation at a distance of $1 / 3$ (near) and $6 \mathrm{~m}$ (far) were conducted both pre and postoperatively. An additional near measurement was obtained after $1 \mathrm{~h}$ mono-ocular occlusion of the non-dominant eye, or by habitually deviating the eye to measure the largest angle of deviation. Post-occlusion near measurement was obtained with an additional +3.00 D sphere over each eye before permitting the patient to regain binocular fusional ability. The angles of deviation when gazing above, below, left, and right were measured in all the patients. Sensory tests, including the Worth-4-dot, Titmus stereotest, and Lang test, were conducted.

\section{Operation}

Every surgery was performed by a single surgeon $(\mathrm{MMK})$ and under general anesthesia. The unilateral R\&R procedure was performed with Parks' method based on the patients' angle of deviation determined the day before the operation (Table 1).

\section{Postoperative evaluation}

The angle of deviation that was measured during the first follow-up visit within a week of surgery was defined as an immediate postoperative deviation. The patient was followed up at 1, 3, 6, and 12 months after the surgery, and every 6 months thereafter. Less than 10 prism diopter (PD) of exotropia and less than 5 PD of esotropia were defined as indicators of a successful surgery.

Recurrence was defined by over 11 PD of exotropia at any time during the follow-up, and overcorrection as indicated by over 5 PD of esotropia was confirmed for more than 3 months.

\section{Statistical analysis}

The surgical outcomes and factors for analysis of significance were based on gender, patient age at surgery, and angle of deviation before surgery as well as immediately after surgery and at 1, 3, 6, and 12 months after surgery. For statistical analysis, logistic regression analysis, the Kaplan-Meier survival test, the independent $t$-test, and the $\chi^{2}$ analysis were used with significance level of $P$-value $<0.05$. All statistical data were analyzed using SPSS software for Windows, version 15.0 (SPSS, Inc., Chicago, IL, USA).

\section{Results}

Among the 489 patients, 209 belonged to the success group and 280 to the recurrence group. The overall

Table 1 Surgical dosage for patients with exotropia

\begin{tabular}{lcc}
\hline Prism diopters & $\begin{array}{c}\text { Recession amounts } \\
\text { of lateral rectus }\end{array}$ & $\begin{array}{c}\text { Resection amounts } \\
\text { of medial rectus }\end{array}$ \\
\hline 25 & 4 & 3 \\
30 & 4 & 4 \\
35 & 5 & 4 \\
40 & 5 & 5 \\
45 & 7 & 5 \\
50 & 8 & 5 \\
55 & 8 & 6 \\
60 & 10 & 6 \\
\hline
\end{tabular}


Table 2 Characteristics of patients with intermittent exotropia Characteristic

\begin{tabular}{lc}
\hline Gender (male:female) & $222: 267$ \\
Family history $^{\mathrm{a}}$ & $41: 448$ \\
Photophobia (presence: absence) & $330: 159$ \\
Diplopia & 9 \\
Age at onset in years (range) & $4.03 \pm 3.63(0-29)$ \\
Age at operation in years (range) & $8.88 \pm 6.15(3-43)$ \\
Dcc before operation & $32.94 \pm 5.98(25-60)$ \\
\hline
\end{tabular}

Abbreviation: Dcc, distance deviation with correction.

${ }^{\text {a}}$ Family history: limited in first-degree.

success rate was $42.7 \%$. There were no overcorrected patients. The number of male and female patients was $222(45.4 \%)$ and $267(54.6 \%)$, respectively, and the mean age at surgery was $8.9 \pm 6.2(3-43)$ years. The mean age of onset was $4.0 \pm 3.6(0-29)$ years. The mean period of follow-up was $27.5 \pm 18.0(12-126)$ months. The mean angle of deviation before the surgery was $32.9 \pm 6.0$ (25-60) PD (Table 2).

The frequency of exotropia was ascertained by a questionnaire; exotropia was first incidentally observed by an ophthalmologist or by the patients' close associates (mother's friends or teachers in kindergarten or in school) in 206 (42.1\%) subjects.

Among the 283 subjects who responded to the question, $17.3,15.9$, and $19.8 \%$ were found to experience exotropia of $11-20 \%, 21-30 \%$, and $31-40 \%$ at waking time, respectively, with more than half of the subjects presenting 11-40\% exotropia.

By defining survival as the time until recurrence, the mean duration of survival was $31.2 \pm 1.7$ months (range: 1-78). Recurrence rate by duration of follow-up period according to the analysis of survival was $5.3 \%$ at 1 month, $16 \%$ at 3 months, $27.6 \%$ at 6 months, $41.9 \%$ at 12 months, $60.7 \%$ at 2 years, $70.8 \%$ at 3 years, $74.5 \%$ at 4 years, and $77.9 \%$ at 5 years. The recurrence rate increased considerably with increased duration of follow-up (Figure 1).

There were no statistically significant differences in gender, photophobia, or family history between the success and recurrence groups (the $\chi^{2}$-test, $P>0.05$ ). However, differences in age at onset, age at surgery, immediate postoperative and 1-, 3-, 6-, and 12-month postoperative angle of deviation showed statistical significance (independent $t$-test, $P<0.05$; Table 3 ).

Univariate logistic regression analysis revealed that larger the measures of immediate postoperative deviation, the higher the increase in the recurrence rate (odds ratio: 1.102, $P=0.000$ ). Further, older the age of either at onset (odds ratio: $0.870, P=0.000$ ) or at surgery (odds ratio: $0.920, P=0.000$ ), the larger the decrease in recurrence rate. Multivariate logistic regression analysis was performed with selected independently significant

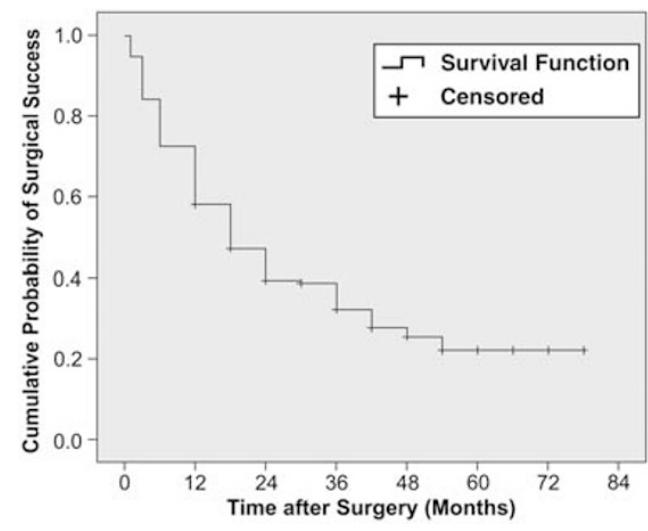

Figure 1 Kaplan-Meier survival curve showing the cumulative probability of surgical success following a unilateral recessionresection procedure. This survival curve indicates that the estimated mean time to surgical failure is $31.2 \pm 1.7$ months.

Table 3 Comparison of characteristics of the success group with the recurrence group

\begin{tabular}{lccc}
\hline Characteristic & $\begin{array}{c}\text { Success } \\
\text { group }\end{array}$ & $\begin{array}{c}\text { Recurrence } \\
\text { group }\end{array}$ & P-value \\
\hline Gender (male : female) & $98: 111$ & $124: 156$ & $0.567^{\mathrm{a}}$ \\
Family history & $19: 190$ & $22: 258$ & $0.847^{\mathrm{a}}$ \\
Photophobia & $141: 68$ & $189: 91$ & $0.993^{\mathrm{a}}$ \\
Age at onset (years) & $4.98 \pm 4.06$ & $3.32 \pm 3.11$ & $0.000^{\mathrm{b}}$ \\
Age at operation (years) & $10.51 \pm 7.31$ & $7.67 \pm 4.79$ & $0.000^{\mathrm{b}}$ \\
Dcc at pre-op & $33.52 \pm 6.88$ & $32.52 \pm 5.17$ & $0.079^{\mathrm{b}}$ \\
Dcc at post-op & $-0.79 \pm 4.67$ & $1.20 \pm 4.51$ & $0.000^{\mathrm{b}}$ \\
Dcc at 1 month & $0.64 \pm 2.85$ & $4.76 \pm 4.81$ & $0.000^{\mathrm{b}}$ \\
Dcc at 3 month & $1.60 \pm 3.26$ & $7.61 \pm 5.53$ & $0.000^{\mathrm{b}}$ \\
Dcc at 6 month & $1.98 \pm 3.47$ & $10.87 \pm 5.26$ & $0.000^{\mathrm{b}}$ \\
Dcc at 12 month & $2.93 \pm 3.56$ & $13.77 \pm 6.00$ & $0.000^{\mathrm{b}}$ \\
\hline
\end{tabular}

Abbreviations: Dcc, distance deviation with correction; post-op, immediate postoperative; pre-op, preoperative.

${ }^{\text {a }} \chi^{2}$-test.

' Independent samples $t$-test.

factors, such as age at onset, age at surgery, and immediate postoperative deviation, in order to analyze the effects on recurrence rate. The result of the analysis showed that all factors had significant effects on recurrence rate. Recurrence rate decreased with increased age at onset (odds ratio: $0.930, P=0.002$ ) and age at surgery (odds ratio: $0.905, P=0.012$ ), and it increased with increased immediate postoperative deviation (odds ratio: $1.143, P=0.000$ ). Differences in gender, family history, frequency, photophobia, and preoperative deviation between groups were not significant.

\section{Discussion}

The success rate of the surgery in this study was $42.7 \%$. Other studies ${ }^{8,10-12}$ have reported a success rate of 
32.8-83.3\% for unilateral R\&R procedure in intermittent exotropia. The direct comparison between these studies is limited because of differences in the definition of successful surgery, size of each study, and duration of follow-up. For example, the criteria for subjects in this study differed from those of Pratt-Johnson et $a l^{17}$ in which a unilateral $R \& R$ procedure was performed on 95 out of 100 subjects, and bilateral lateral rectus recession was performed on the remaining five subjects.

The definition of success rate of surgery varies by study. Maruo et $a l^{8}$ define exotropia between orthotopic and exotropia of 4 PD or less as successful surgery. Hardesty et al ${ }^{15}$ considered a surgery successful when the residual angle of deviation at both far and near distance was absent for at least 12 months, and the Titmus stereotest reveals a certain level of stereopsis. Kushner et $a l^{11}$ consider esotropia of less than 5 PD or extropia of less than $10 \mathrm{PD}$ as a successful surgery. Jeoung et al $^{12}$ define esotropia and exotropia of less than 10 PD within 6 months of follow-up as a successful surgery.

Controversies still abound in defining successful surgery, but the assertion that absolute orthophoria is necessary for successful surgery seems far from realistic. The criteria for our study are comparable to those of Kushner et al. ${ }^{13}$ Table 4 presents the comparisons of the total numbers of subjects, duration of follow-up, and the success rates of previous studies.

In our study, age at onset, age at surgery, and angle of deviation at distance immediately after surgery and $1,3,6$, and 12 months after surgery were found to have statistically significant effects on recurrence rates.
Previous results have varied in concluding whether age at surgery or other factors are a determining factor for the success of surgery. Chia et $a l^{14}$ reported that age at surgery and preoperative angle of deviation are not prognostic factors for the success of surgery. Gezer et $a l^{13}$ reported that age at surgery is not a prognostic factor for the success of surgery, but preoperative degree of deviation, the amount of correction by surgery, and preoperative refractory error are prognostic factors. Roh et $a l^{20}$ also suggested that age at surgery is not associated with the success of surgery, and stereopsis is the only prognostic factor for the success of surgery. Oh et $a l^{9}$ suggested that overcorrection of postoperative 10 PD or more is the only prognostic factor.

In contrast, Pratt-Johnson et $a l^{17}$ asserted that age at surgery is the most important factor for the success of surgery, and that the surgery should be performed before a patient turns 4 years old. Knapp ${ }^{18}$ and Hiles ${ }^{19}$ suggested that early surgical intervention is recommended to prevent abnormal sensory adaptations.

In South Korea, Paik et $a l^{21}$ reported that surgery was successful in $83 \%$ of the patients who underwent the surgery before they turned 24 months old, and that five out of six patients obtained favorable stereopsis. As a basis for this assertion, Knapp ${ }^{18}$ suggested that when the angle of deviation is acutely detrimental to fusion and stereopsis, surgery should be performed on young patients to prevent sensory abnormalities and to minimize the tendency toward recurrence of exotropia.

Haik, ${ }^{22}$ however, reported that postoperative overcorrection in pediatric patients less than 4 years of

Table 4 Comparison of success rates for surgical correction of intermittent exotropia

\begin{tabular}{|c|c|c|c|c|}
\hline & Subject & Surgery type & Success definition & Findings \\
\hline Kushner et $_{a l^{11}}$ & $\begin{array}{l}36 \text { patients with basic } X(T) \text {, } \\
\text { randomly assigned }\end{array}$ & $\begin{array}{l}\text { R\&R: } 17 \\
\text { BLR: } 19\end{array}$ & $5 \mathrm{E}-10 \mathrm{X}$ & $\begin{array}{l}\text { R\&R: } 82 \% \text { success } \\
\text { BLR: } 52 \% \text { success }\end{array}$ \\
\hline Pratt-Johnson et al ${ }^{17}$ & 100 patients, 59 with 1-year follow-up & $\begin{array}{l}\text { R\&R: } 95 \\
\text { BLR: } 5\end{array}$ & $0-10 \times \mathrm{T}$ & Success: $45.7 \%$ \\
\hline \multirow[t]{2}{*}{ Maruo et $a l^{8}$} & 666 patients, with 4 -year follow-up & R\&R: 298 & $0-4 \mathrm{XT}$ & $\begin{array}{l}\text { R\&R (Success) } \\
60.4 \% \text { (1 month), } \\
32.8 \% \text { (4 years) }\end{array}$ \\
\hline & & BLR: 349 & & $\begin{array}{l}\text { BLR (Success) } \\
60.2 \% \text { ( } 1 \text { month), } \\
66 \% \text { (4 years) }\end{array}$ \\
\hline Jeoung et al ${ }^{12}$ & $\begin{array}{l}124 \text { patients, } \\
\text { 6-months follow-up }\end{array}$ & $\begin{array}{l}\text { R\&R: } 66 \\
\text { BLR: } 58\end{array}$ & 10ET-10XT & $\begin{array}{l}\text { R\&R: } 83.3 \% \text { success } \\
\text { BLR: } 48.3 \% \text { success }\end{array}$ \\
\hline Ekdawi et $a^{7}$ & $\begin{array}{l}184 \text { patients, } \\
0-25.8 \text { years follow-up }\end{array}$ & $\begin{array}{l}\text { R\&R: } 33 \\
\text { BLR: } 27\end{array}$ & 10ET-10XT & $\begin{array}{l}\text { R\&R: } 58 \% \text { success } \\
\text { BLR: } 56 \% \text { success }\end{array}$ \\
\hline Our study & 489 patients, minimal 1 year follow-up & R\&R: 489 & 5ET-10XT & $\begin{array}{l}\text { R\&R } \\
\quad 58.1 \% \text { ( } 1 \text { year) } \\
46.9 \% \text { ( } 2 \text { years }) \\
42.7 \% \text { (Final) }\end{array}$ \\
\hline
\end{tabular}

Abbreviations: BLR, bilateral lateral rectus recession; E, esophoria; ET, esotropia; R\&R, unilateral resect-recession procedure; X, exophoria; XT, exotropia. 
age could result in decreased stereopsis function, loss of binocular vision, and secondary sensitivity adaptation for esotropia. Von Noorden et $a l^{23}$ recommended that the surgery be delayed until the age of 4 years or older to prevent overcorrection in infants. Maruo et $a l^{9}$ reported that the rate of orthotropia or mini-microtropia was higher among patients younger than 3 years and older than 11 years of age, and that early surgery is not necessary when the patient is over 4 years of age.

This result is contrary to that of the study by Richard and Park in which the frequency of overcorrection was found to be higher when the surgery is performed at younger age. The reason for the higher recurrence rate when surgery is performed at younger age is postulated as follows:

First, there is unreliability of preoperative measurements. As the reliability of preoperative measurements is relatively low in younger patients, possibilities of undercorrection cannot be eliminated. On the contrary, because the reliability of deviation and visual acuity measurement increases with older patients, possibilities of undercorrection and recurrence decrease. To avoid this inaccuracy, Kushner ${ }^{24}$ recommended that (1) the deviation be measured while the patient fixates on an outdoor target, (2) the monocular occlusion be achieved in patients with exotropia before deciding on the amount of surgery, and (3) intervention be performed on the basis of the largest angle measured.

Second, as reported in the study by Nusz et $a l^{2}$ which examined a population-based cohort over a 20-year period, the proportion of aggravation of exodeviation by 10 or more PD was $23.1 \%$ at 5 years and $52.8 \%$ at 20 years in intermittent exotropia without surgery. In addition, Ekdawi et $a l^{7}$ reported that the probability of developing an angle of deviation $>10$ PD after the first surgery was $54 \%$ at 5 years, $76 \%$ at 10 years, and $86 \%$ at 15 years. This indicates that the angle of deviation of exotropia became more severe over time. As the angle of deviation has a tendency toward exodeviation over time, it is expected that the angle of deviation could become more stable with an increase in age.

Another possible reason for a high rate of recurrence may be the differences in fusional ability. Older patients often have smaller deviations, lower exotropic frequencies, or no photophobia, which delay hospital visits. Compared with younger patients, older individuals may have better fusional ability and stereopsis. Although the frequency of exotropia and existence of photophobia do not show any statistically significant relation to recurrence rate $(P=0.692)$, patients with successful surgery are generally thought to have better fusional ability before surgery.

Moreover, recurrence rates were lower among surgeries performed on older patients. However, not only age but dysfunction of binocular fusional ability and degree of deviation should also be considered as predictors of surgical outcomes. ${ }^{23}$ Gezer et al ${ }^{13}$ reported that a preoperative exodeviation of $40 \mathrm{PD}$ or more had a significantly greater likelihood of recurrence because of a positive correlation between preoperative and postoperative deviations. Similarly, Scott et $a l^{25}$ reported that the degree of preoperative exodeviation, patient age at surgery, status of refraction, degree of anisometropia, and difference in the angle of deviation at the distance between upward gaze and downward gaze were prognostic factors.

However, most of the previous studies reported that there was no correlation between degree of preoperative deviation and recurrence rate. Our study also found that there was no correlation between degree of preoperative deviation and degree of postoperative exodeviation, and there was no statistically significant difference in preoperative deviation between the success group and the recurrence group $(P>0.05)$.

Pratt-Johnson et $a l^{17}$ reported that postoperative overcorrection, a factor that influences the recurrence rate of intermittent exotropia, had no influence on the final surgical outcome, and that esotropia due to postoperative overcorrection could result in amblyopia and decreased binocular vision. Most other studies, however, reported that postoperative overcorrection gave higher success rates. Scott et $a l^{25}$ viewed 4-14 PD as a desirable initial overcorrection, whereas this was determined to be at 0-9 PD by Ruttum ${ }^{26}$ and 10-20 PD by von Noorden. ${ }^{23}$ Raab and Parks ${ }^{27}$ recommended 10-20 PD of esotropia in the primary position on the second or third postoperative day.

Similar to the results of other studies, the recurrence rate in our study significantly decreased with decreases in the angle of deviation immediately after surgery and at $1,3,6$, and 12 months after surgery. This result is believed to be attributable to the possible mechanism that immediate postoperative overcorrection resulting in diplopia, reduction of suppression, and stimulation of fusion capability gave long-term stability of ocular alignment.

In this study, gender and preoperative angle of deviation did not have significant influence on the recurrence rate in both success and recurrence outcomes.

In conclusion, our study demonstrated that the recurrence of intermittent exotropia was influenced by age at onset, age of the patient at surgery, angle of deviation immediately after surgery, and at 1, 3, 6, and 12 months after surgery. In addition, we found that the success rate of surgery decreased over the course of follow-up. Therefore, immediate postoperative overcorrection, as well as angle of deviation at follow-up, should be accurately measured, and patient age at 
surgery should be seriously considered in postoperative overcorrection. However, as this study was focused only on $R \& R$, further studies are required to ascertain whether age of the patient at the time of surgery has a critical role in determining outcomes of other treatments for intermittent exotropia.

\section{Summary}

What was known before

- There have been a number of reports of possible prognostic factors affecting surgical outcomes such as preoperative degree of exodeviation, duration of postoperative follow-up, surgical procedures, types of exotropia, and stereopsis for intermittent exotropia surgery. However, controversies still abound.

\section{What this study adds}

- In conclusion, our study demonstrated that the recurrence of intermittent exotropia was influenced by age at onset, age of the patient at surgery, and angle of deviation immediately after surgery and at 1, 3, 6, and 12 months postoperative. In addition, we found that the success rate of surgery decreased over the course of follow-up.

\section{Conflict of interest}

The authors declare no conflict of interest.

\section{References}

1 Govindan M, Mohney BG, Diehl NN, Burke JP. Incidence and types of childhood exotropia - A population-based study. Ophthalmology 2005; 112: 104-108.

2 Nusz KJ, Mohney BG, Diehl NN. The course of intermittent exotropia in a population-based cohort. Ophthalmology 2006; 113: 1154-1158.

3 Preslan MW, Novak A. Baltimore vision screening project. Ophthalmology 1996; 103: 105-109.

4 Choi KW, Koo BS, Lee HY. Preschool vision screening in Korea; results in 2003. J Korean Ophthalmol Soc 2006; 47: 112-120.

5 Yu YS, Kim SM, Kwon JY. Preschool vision screening in Korea; preliminary study. J Korean Ophthalmol Soc 1991; 32: 1092-1096.

6 Figueira EC, Hing S. Intermittent exotropia: comparison of treatments. Clin Experiment Ophthalmol 2006; 34: 245-251.

7 Ekdawi NS, Nusz KJ, Diehl NN, Mohney BG. Postoperative outcomes in children with intermittent exotropia from a population-based cohort. J AAPOS 2009; 13: 4-7.
8 Maruo T, Kubota N, Sakaue T, Usui C. Intermittent exotropia surgery in children: long term outcome regarding changes in binocular alignment. A study of 666 cases. Binocul Vis Strabismus Q 2001; 16: 265-270.

9 Oh JY, Hwang JM. Survival analysis of 365 patients with exotropia after surgery. Eye 2006; 20: 1268-1272.

10 Burian HM, Spivey BE. The surgical management of exodeviations. Am J Ophthalmol 1965; 59: 603-620.

11 Kushner BJ. Selective surgery for intermittent exotropia based on distance/near differences. Arch Ophthalmol 1998; 116: $324-328$

12 Jeoung JW, Lee MJ, Hwang JM. Bilateral lateral rectus recession vs unilateral recess-resect procedure for exotropia with a dominant eye-Reply. Am J Ophthalmol 2006; 142: 708-709.

13 Gezer A, Sezen F, Nasri N, Gozum N. Factors influencing the outcome of strabismus surgery in patients with exotropia. J AAPOS 2004; 8: 56-60.

14 Chia A, Seenyen L, Long QB. Surgical experiences with two-muscle surgery for the treatment of intermittent exotropia. J AAPOS 2006; 10: 206-211.

15 Hardesty HH, Boynton JR, Keenan JP. Treatment of intermittent exotropia. Arch Ophthalmol 1978; 96: 268-274.

16 Beneish R, Flanders M. The role of stereopsis and early postoperative alignment in long-term surgical results of intermittent exotropia. Can J Ophthalmol 1994; 29: 119-124.

17 Pratt-Johnson JA, Barlow JM, Tillson G. Early surgery in intermittent exotropia. Am J Ophthalmol 1977; 84: 689-694.

18 Knapp P. Management of exotropia in Transactions of the New Orleans Academy. CV Mosby: St Louis, MO, 1971.

19 Hiles DA, Biglan AW. Early surgery of infantile exotropia. Trans Pa Acad Ophthalmol Otolaryngol 1983; 36: 161-168.

20 Roh JH, Paik HJ. Clinical study on factors associated with recurrence and reoperation in intermittent exotropia. J Korean Ophthalmol Soc 2008; 49: 1114-1119.

21 Paik HJ, Yim HB. Clinical effect of early surgery in infantile exotropia. Korean J Ophthalmol 2002; 16: 97-102.

22 Haik GM. Transections of the New Orleans Academy of Ophthalmology. Mosby: St Louis, 1962.

23 von NGK, Campos EC. Exodeviation, 6th ed. CV Mosby: St Louis, 2002.

24 Kushner BJ. The distance angle to target in surgery for intermittent exotropia. Arch Ophthalmol 1998; 116: 189-194.

25 Scott AB, Mash AJ, Jampolsky A. Quantitative guidelines for exotropia surgery. Invest Ophthalmol 1975; 14: 428-436.

26 Ruttum MS. Initial versus subsequent postoperative motor alignment in intermittent exotropia. J of AAPOS 1997; 1: 88-91.

27 Raab EL, Parks MM. Recession of the lateral recti. Early and late postoperative alignments. Arch Ophthalmol 1969; 82: 203-208. 